\title{
The Antibacterial Effect of Additional Photodynamic Therapy in Failed Endodontically Treated Teeth: A Pilot Study
}

\author{
Mohammad Asnaashari ${ }^{1}$, Hamed Homayuni², Payam Paymanpour ${ }^{3^{*}}$ \\ 'Laser Application in Medical Sciences Research Center, Shahid Beheshti University of Medical Sciences, Tehran, Iran \\ ${ }^{2}$ Department of Endodontics, School of Dentistry, Qazvin University of Medical Sciences, Qazvin, Iran \\ ${ }^{3}$ Department of Endodontics, School of Dentistry, Shaid Beheshti University of Medical Sciences, Tehran, Iran
}

\author{
*Correspondence to \\ Payam Paymanpour, DDS, MSc; \\ Department of Endodontics, \\ School of Dentistry, Shaid Beheshti \\ University of Medical Sciences, \\ Tehran, Iran. \\ Tel:+98-9123847889 \\ Fax: 098-2122413896 \\ Email: \\ Payam_Paymanpour@yahoo.com
}

Published online 27 October 2016

\begin{abstract}
Introduction: Root canal therapy as a routine dental procedure has resulted in retention of millions of teeth that would otherwise be lost. Unfortunately, successful outcomes are not always achievable within initial endodontic treatments, and that necessitates further treatment. Nonsurgical retreatment is the first choice in most clinical situations. The aim of this clinical pilot study was to assess the effect of additional photodynamic therapy (PDT) on intraradicular bacterial load following retreatment of failed previously root treated teeth. Methods: Thirty single-rooted/canalled endodontically treated matured teeth (in 27 healthy patients) accompanied by apical periodontitis (AP) were selected for this study. Standard protocol was followed for nonsurgical retreatment of each tooth. Microbiological samples were taken after establishment of apical patency, finished cleaning/shaping procedure, and PDT (665 nm, 1 W, 240 seconds). All samples were cultured for 72 hours and colonyforming unit (CFU) was counted. McNemar test was used for statistical analysis of the data. The level of significance was set at 0.001 .

Results: Routine cleaning and shaping resulted in twenty four negative (80\%) out of 30 cultures. Four additional negative results were obtained after additional PDT (93.3\%). The addition of PDT to routine procedures significantly enhanced the number of bacteria-free samples $(P<0.001)$.

Conclusion: Regarding elimination of intraradicular microbiota, additional PDT may increase the effectiveness of conventional chemomechanical preparation in previously root filled teeth accompanied by AP. Well controlled randomized clinical trials should be planned for future.

Keywords: Apical periodontitis; Endodontic; Photodynamic therapy.
\end{abstract}

\section{Introduction}

It is well documented that microbial flora is the main cause of dental pulp necrosis and apical periodontitis (AP). ${ }^{1}$ Pre-obturation bacterial elimination from root canal system significantly affects healing of human AP. Accordingly, negative and positive cultures prior to root canal filling met with $94 \%$ and $68 \%$ treatment success (complete periapical healing), respectively. ${ }^{2}$

Persistent microorganisms play a significant role in endodontic failure of the majority of root-filled human teeth with therapy resistant periapical lesions. ${ }^{3}$ Contamination with cultivable bacteria is reported in $40 \%-60 \%$ of instrumented canals following $\mathrm{NaOCl}$ syringe-needle irrigation. ${ }^{4}$ Regarding antimicrobial efficacy of routine chemo-mechanical endodontic procedures, it has been suggested to develop adjunctive strategies to target residual microbiota, for achieving higher healing rates in teeth with infected root canals. ${ }^{5}$ Reaching of the laser light into areas that would not have otherwise been accessed with traditional methods, ${ }^{6}$ and its antibacterial effects ${ }^{7-9}$ made high-power lasers promising in root canal disinfection. However, the risks of dentin charring, ankylosis, resorptions, and necrosis of periradicular tissues were reported for high-power lasers. ${ }^{10}$ On the other hand, promising antibacterial results have been reported for photodynamic therapy (PDT) in oral pathologic conditions such as periimplantitis, ${ }^{11}$ periodontal disease ${ }^{12}$ and dental carious lesions. ${ }^{13}$ PDT, first developed as a cancer therapy method, requires three basic elements: a nontoxic photosensitizer/photoactivated substance, a light source, and tissue oxygen. Photosensitizer's (PS's) excitation with a suitable light source produces highly cytotoxic singlet oxygen, causing bacterial destruction. ${ }^{14,15}$ This bactericidal mechanism totally differs from that of high-power laser ther- 
mal effects (neodymium-doped yttrium aluminium garnet, Nd:YAG) and/or its strong water absorption properties (erbium-doped yttrium aluminium garnet, Er:YAG). ${ }^{8}$ The evidence grade for whether lasers can be recommended as an adjunct to chemomechanical disinfection of infected root canals is insufficient. ${ }^{16}$ Regarding one-session endodontic treatment, PDT (PS phenothiazine chloride and diode laser) showed moderate angiogenesis and fibrogenesis with the absence of inflammatory cells in the periapical region in dog teeth with $\mathrm{AP}^{17}$ Another in vivo study reported the presence of collagen fibers and blood vessels and absence of inflammatory cells in specimens treated by PDT, compared with severe inflammation with edematous areas and fiber dissociation in one-session treatment ${ }^{18}$; the authors suggested that the PDT treated cases would probably exhibit a more evident repair process, if a longer evaluation period was used. Enterococcus faecalis is the species most frequently associated with refractory AP. ${ }^{19,20}$ Although several studies reported effectiveness of PDT against E. faecalis, ${ }^{7,21-30}$ its efficacy in eliminating $E$. faecalis from infected root canals remained questionable and well-designed studies are needed to examine the role of PDT as a bactericidal agent in infected root canals. ${ }^{31}$ Based on current evidence, there is limited clinical information available on the use of PDT in root canal disinfection. ${ }^{32}$

The aim of the present clinical study was to evaluate the antibacterial effect of additional PDT in failed previously treated teeth with AP.

\section{Methods}

For this study, 30 single-rooted/canalled endodontically treated matured teeth accompanied by AP were selected in 27 healthy patients. Teeth with intracanal posts, radiographic well-performed root canal therapy, separated endodontic instruments, need for chemical solvent(s), inability to regain apical patency, and vertical root fracture (VRF) suspicious circumstances, open apices, overextension of root canal filling materials were excluded. After giving clear explanation, written informed consent was obtained from all healthy participants. The presence of AP (2-5 mm) should have been evident in parallel pre-operative radiographs.

\section{Clinical Procedures}

All clinical procedures were performed by a senior post-graduate student of endodontics, department of endodontics, Shahid Beheshti University of Medical Sciences, Tehran, Iran. After one minute of use of $0.2 \% \mathrm{ch}$ lorhexidine gluconate mouth rinse, local anaesthesia was administered and dental rubber dam was applied. Tooth surface disinfection was done using $2 \%$ chlorhexidine gluconate. Coronal restoration and caries (if any) were removed with suitable high speed and low speed burs. After establishment of straight line access, root canal obturating materials were bypassed and removed with \#15 to \#25 K-file (Mani, Japan). Apical patency was established using a \#10 K-file. Subsequently, root canal was irrigated with 1
$\mathrm{mL}$ sterile normal saline and dried out using three sterile paper points (Ariadent, Tehran, Iran). The paper points were used as first microbiologic sampling and combined for initial colony-forming unit (CFU) determination. The paper points were deposited in a sterile bottle with fresh Moller's VMGA (viability medium Göteborg anaerobic) III transport medium. The first microbiological sampling confirmed that none of the teeth were bacteria-free. Crown-down root canal preparation was performed with \#3, and \#2 gates glidden burs (Mani, Japan) and ProTaper Universal (Dentsply Maillefer, Ballaigues, Switzerland) rotary instruments (S2-F3) $1 \mathrm{~mm}$ short of radiographic apex. Between each instrument, the root canal was irrigated with $2.5 \% \mathrm{NaOCl}$ as endodontic irrigant $(10 \mathrm{~mL}$ in total). Smear layer was removed with $17 \%$ EDTA and 5 $\mathrm{mL}$ of sterile saline was used to rinse off any antimicrobial agent residue. The canal was then dried with another three paper points to form the second microbiological sampling. PS solution was delivered into the root canal $(0.5 \mathrm{~mL})$ using a 27 gauge needle, and left for 2 minutes. Diode laser irradiation was performed using a new fiber for each tooth (240 seconds and total energy of 9.6 J). After $10 \mathrm{~mL}$ sterile saline irrigation, another three sterile paper points were used for drying the root canal (third microbiological sampling). Root canal space was then laterally obturated with AH 26 sealer (DENTSPLY Maillefer, Ballaigues, Switzerland) and gutta percha. All access cavities were temporarily sealed (Fuji II glass ionomer, GC America, Alsip, IL) and patients were referred to restorative department for placement of proper permanent coronal restoration.

\section{Photosensitizer and Light Source}

Methylene blue (MB) was used as PS because of its low molecular weight and cationic nature. ${ }^{33} \mathrm{MB}$ targets both gram-negative and positive oral microbiota. ${ }^{34}$ In gram-negative bacteria, the dye passes across the outer membrane and interacts with lipopolysaccharide molecule that produces $\mathrm{MB}$ dimmers participating in photosensitization. ${ }^{35}$

$50 \mathrm{mg} / \mathrm{mL}$ MB (Sigma, St. Louis, MO, USA) immediately filtered and sterilized was used. A diode laser unit (BWTEK Inc, Newark, DE) provided $665 \mathrm{~nm}$ light with an output power of $1 \mathrm{~W}$. A power meter (Ophir Optronics LTD, Danvers, MA) was used for power quantification. A 300 micron optical fiber was coupled to the unit for light delivery into the root canal. Apico-coronal spiral movement of the fiber (4 times per minute) was performed for intracanal light diffusion.

\section{Microbiological Analyses}

Culture method was used for microbial load assessment. However, no microbial identification was made during the procedure. The paper points were removed from the anaerobic transport medium (VMGA III), placed inside a 1.5-mL microcentrifuge with brain-heart infusion (BHI) broth, and positioned in a vortex for 30 seconds on arrival at microbiological facility. One hundred-microliter 
aliquots were added to wells of a 96-well plate for serial dilution and streaking on square BHI agar plates for CFU enumeration. The plates were placed inside a microaerophilic chamber with $5 \%$ oxygen, $15 \%$ carbon dioxide and $80 \%$ nitrogen, and incubated for 72 hours at $37^{\circ} \mathrm{C}$. At each stage of the clinical procedure (initial, after chemo-mechanical preparation and after PDT), the CFUs were counted. Survival fractions were calculated from each tooth taking into account its initial bacterial load. $\mathrm{McNemar}$ test was used for statistical analysis of the data. The level of significance was set at 0.001 .

\section{Results}

In this study, microbiologic samples were obtained from thirty previously treated teeth with AP that should undergo endodontic retreatment. Table 1 shows negative and positive cultures following conventional method, with and without PDT. Routine cleaning and shaping resulted in twenty four negative cultures (80\%). Four additional negative results were obtained after PDT application (93.3\%). However, culture results remained positive even after PDT in two teeth. The addition of PDT to routine procedures significantly enhanced the number of bacteria-free samples $(P<0.001)$.

\section{Discussion}

Even in root canal-treated teeth with recalcitrant lesions, the major cause of post treatment disease is a persistent or secondary intraradicular infection. This has been confirmed by studies investigating the microbiologic conditions of root canals associated with persistent AP. ${ }^{36,37}$ Presence of persistent cultivable bacteria at the time of obturation reduced the treatment success rate from $94 \%$ to $68 \% .^{2}$ Similarly, success rate in teeth with negative cultures before obturation was significantly higher than teeth with positive cultures. ${ }^{38}$ Recent studies highlighted the antimicrobial potential of PDT in endodontics. ${ }^{39-41}$ High elimination rates of endodontic pathogens were reported as a promising ex vivo and in vivo effects of PDT. ${ }^{24,42,43}$ Little to no cytotoxicity of $\mathrm{PDT}^{22,44}$ hence its high selectivity, has been demonstrated. The lethal activity of PDT against target cells is based on photochemical events and not thermal effects, as opposed to many laser therapy techniques. $^{45}$

The aim of the present study was to assess potential antibacterial effects of PDT in failed previously root filled teeth. In this study, application of PDT after routine retreatment procedures significantly reduced the number of positive cultures. This result corresponds with Garcez et al. ${ }^{46}$ They used polyethylenimine chlorine (e6) with a $660-\mathrm{nm}$ wavelength diode laser at $40-\mathrm{mW}$ power for 240 seconds, and reported significant further reduction of bacterial load with PDT as an adjuvant to conventional endodontic treatment, and its effectiveness against multidrug resistant bacteria.

In the present study, MB dye was used as PS. Xu et $\mathrm{al}^{44}$ reported that MB-mediated PDT may be effective in a clinical setting as an adjunctive technique for endodontic
Table 1. Culture Results of Different Microbiologic Samplings During Endodontic Retreatment Procedures

\begin{tabular}{lcc}
\hline \multirow{2}{*}{ Sampling } & \multicolumn{2}{c}{$\begin{array}{c}\text { Culture Results } \\
\text { No. (\%) }\end{array}$} \\
\cline { 2 - 3 } & $0(0)$ & Positive \\
\hline First & $24(100)$ \\
$\begin{array}{l}\text { Second (after } \\
\text { chemomechanical } \\
\begin{array}{l}\text { Preparation) } \\
\text { Third ( after additional } \\
\text { PDT) }\end{array}\end{array}$ & $6(20)$ \\
\hline Abbreviacteria-Free) & $28(93.3)$ & $2(6.7)$ \\
\hline
\end{tabular}

Abbreviation: photodynamic therapy.

disinfection without harming cells in the periapical region. MB dye is a widely used phenothiazinium-based PS for PDT. Its tumor and microbial cells selectivity is due to the electrostatic interaction between this positive charge molecule and the negative charge on the external surface of the target cells. ${ }^{34}$ Hydrophilicity, low molecular weight and the positive charge of $\mathrm{MB}$ allow its passage through the porin-protein channels of gram-negative bacteria external membranes. It was demonstrated that MB interacts with anion lipopolysaccharidic macromolecules, which results in $\mathrm{MB}$ dimmers. ${ }^{35} \mathrm{MB}$ was used according to several previous studies. ${ }^{42,43,47}$

Regarding root canal disinfection, most of recent studies did not confirm a significant improvement for PDT as a substitute for current disinfection methods. Hence, in the present study it was used as an adjunct to the routine procedures. ${ }^{26,39}$

In this study, additional PDT led to $93.3 \%$ bacteria-free samples, that agrees with a recent systematic review on the effect of PDT in root canal disinfection (91.3\%-100\%). ${ }^{32}$ PDT eliminated four out of six treatment-resistant positive samples. Whereas two remained positive resistant samples did not get bacteria-free. This may stem from the fact that the antibacterial activity of PDT is compromised in the presence of dentin, dentin matrix, pulp tissue, serum, and bacterial remnants (lipopolysaccharides). ${ }^{43,48}$.In addition, presence of largely untouched areas of root canal system is quite common after both rotary and manual endodontic instrumentation. ${ }^{49}$

In the present study, paper points were used for microbiological samplings. However, it should be noted that this technique lacks the ability to test the efficacy of PDT on biofilms.

Because of the heterogeneity in clinical indications and protocols among several studies, there is no available meta-analysis on PDT's root canal disinfection ability. ${ }^{32}$ Further well-designed randomized clinical trials are crucial to strengthen the currently available level of evidence. Although PDT seems promising regarding its additional reduction of the microbial load of root canal systems, it would be beneficial to identify the ideal combination of photosensitizer and light wavelength via preclinical studies. 


\section{Conclusion}

Persistent or reintroduced microorganisms are the major cause of post-treatment disease. ${ }^{3}$ Thus all attempts to eliminate intra-radicular microbiota should be considered as much as possible. If supported by future well designed randomized clinical research, PDT may have efficacy for additional root canal disinfection, especially in failed root canal treated teeth.

\section{Ethical Considerations}

The study protocol was approved by the Ethics Committee of the dental school of Shahid Beheshti University of Medical Sciences, Tehran, Iran (IR.SBMU.RIDS. REC.1395.213).

\section{Conflict of Interests}

There was no conflict of interest for any of the authors to disclose.

\section{References}

1. Kakehashi S, Stanley HR, Fitzgerald RJ. The effects of surgical exposures of dental pulps in germ-free and conventional laboratory rats. Oral Surg Oral Med Oral Pathol. 1965;20:340-349.

2. Sjogren U, Figdor D, Persson S, Sundqvist G. Influence of infection at the time of root filling on the outcome of endodontic treatment of teeth with apical periodontitis. Int Endod J. 1997;30(5):297-306.

3. Nair PN, Sjogren U, Krey G, Kahnberg KE, Sundqvist G. Intraradicular bacteria and fungi in root-filled, asymptomatic human teeth with therapy-resistant periapical lesions: a long-term light and electron microscopic follow-up study. J Endod. 1990;16(12):580588. doi:10.1016/s0099-2399(07)80201-9.

4. Paque F, Laib A, Gautschi H, Zehnder M. Hard-tissue debris accumulation analysis by high-resolution computed tomography scans. J Endod. 2009;35(7):1044-1047. doi:10.1016/j.joen.2009.04.026.

5. Ng R, Singh F, Papamanou DA, et al. Endodontic photodynamic therapy ex vivo. J Endod. 2011;37(2):217222. doi:10.1016/j.joen.2010.10.008.

6. Odor TM, Watson TF, Pitt Ford TR, McDonald F. Pattern of transmission of laser light in teeth. Int Endod J. 1996;29(4):228-234.

7. Bago I, Plečko V, Gabrić Pandurić D, Schauperl Z, Baraba A, Anić I. Antimicrobial efficacy of a high-power diode laser, photo-activated disinfection, conventional and sonic activated irrigation during root canal treatment. Int Endod J. 2013;46(4):339-347.

8. Meire MA, Coenye T, Nelis HJ, De Moor RJ. In vitro inactivation of endodontic pathogens with Nd:YAG and Er:YAG lasers. Lasers Med Sci. 2012;27(4):695-701. doi:10.1007/s10103-011-0940-z.

9. Neelakantan P, Cheng CQ, Mohanraj R, Sriraman P, Subbarao C, Sharma S. Antibiofilm activity of three irrigation protocols activated by ultrasonic, diode laser or Er:YAG laser in vitro. Int Endod J. 2015;48(6):602-610. doi:10.1111/iej.12354.

10. Bahcall J, Howard P, Miserendino L, Walia H. Preliminary investigation of the histological effects of laser endodontic treatment on the periradicular tissues in dogs. J Endod.
1992;18(2):47-51. doi:10.1016/s0099-2399(06)81369-5.

11. Hayek RR, Araujo NS, Gioso MA, et al. Comparative study between the effects of photodynamic therapy and conventional therapy on microbial reduction in ligature-induced peri-implantitis in dogs. J Periodontol. 2005;76(8):1275-1281. doi:10.1902/jop.2005.76.8.1275.

12. Meisel P, Kocher T. Photodynamic therapy for periodontal diseases: state of the art. J Photochem Photobiol B. 2005;79(2):159-170. doi:10.1016/j.jphotobiol.2004.11.023.

13. Walsh LJ. The current status of laser applications in dentistry. Aust Dent J. 2003;48(3):146-155.

14. Dougherty TJ, Gomer CJ, Henderson BW, et al. Photodynamic therapy. J Natl Cancer Inst. 1998;90(12):889905.

15. Hamblin MR, Hasan T. Photodynamic therapy: a new antimicrobial approach to infectious disease? Photochem Photobiol Sci. 2004;3(5):436-450. doi:10.1039/b311900a.

16. Fransson H, Larsson K, Wolf E. Efficacy of lasers as an adjunct to chemo-mechanical disinfection of infected root canals: a systematic review. Int Endod J. 2013;46(4):296307.

17. Silva LAB, Novaes AB Jr, de Oliveira RR, Nelson-Filho P, Santamaria M Jr, Silva RAB. Antimicrobial photodynamic therapy for the treatment of teeth with apical periodontitis: a histopathological evaluation. J Endod. 2012;38(3):360366. doi:10.1016/j.joen.2011.12.023.

18. Borsatto MC, Correa-Afonso AM, Lucisano MP, et al. One-session root canal treatment with antimicrobial photodynamic therapy (aPDT): an in vivo study. Int Endod J. 2016;49(6):511-518. doi:10.1111/iej.12486

19. Fisher K, Phillips C. The ecology, epidemiology and virulence of Enterococcus. Microbiology. 2009;155(Pt 6):1749-1757. doi:10.1099/mic.0.026385-0.

20. Stuart CH, Schwartz SA, Beeson TJ, Owatz CB. Enterococcus faecalis: its role in root canal treatment failure and current concepts in retreatment. $J$ Endod. 2006;32(2):93-98. doi:10.1016/j.joen.2005.10.049.

21. Asnaashari M, Mojahedi SM, Asadi Z, Azari-Marhabi S, Maleki A. A comparison of the antibacterial activity of the two methods of photodynamic therapy (using diode laser $810 \mathrm{~nm}$ and LED lamp $630 \mathrm{~nm}$ ) against Enterococcus faecalis in extracted human anterior teeth. Photodiagn Photodyn Ther. 2016;13:233-237.

22. George S, Kishen A. Advanced noninvasive light-activated disinfection: assessment of cytotoxicity on fibroblast versus antimicrobial activity against Enterococcus faecalis. J Endod. 2007;33(5):599-602. doi:10.1016/j. joen.2007.01.018.

23. George S, Kishen A. Influence of photosensitizer solvent on the mechanisms of photoactivated killing of Enterococcus faecalis. Photochem Photobiol. 2008;84(3):734-740. doi:10.1111/j.1751-1097.2007.00244.x.

24. Komine C, Tsujimoto Y. A small amount of singlet oxygen generated via excited methylene blue by photodynamic therapy induces the sterilization of Enterococcus faecalis. $J$ Endod. 2013;39(3):411-414. doi:10.1016/j. joen.2012.11.051.

25. Kranz S, Guellmar A, Volpel A, Gitter B, Albrecht V, Sigusch BW. Photodynamic suppression of Enterococcus faecalis using the photosensitizer mTHPC. Lasers Surg Med. 2011;43(3):241-248. doi:10.1002/lsm.21046.

26. Bergmans L, Moisiadis P, Huybrechts B, Van Meerbeek B, Quirynen M, Lambrechts P. Effect of photo-activated 
disinfection on endodontic pathogens ex vivo. Int Endod J. 2008;41(3):227-239. doi:10.1111/j.13652591.2007.01344.x.

27. Kishen A, Upadya M, Tegos GP, Hamblin MR. Efflux pump inhibitor potentiates antimicrobial photodynamic inactivation of Enterococcus faecalis biofilm. Photochem Photobiol. 2010;86(6):1343-1349. doi:10.1111/j.17511097.2010.00792.x.

28. Nunes MR, Mello I, Franco GC, et al. Effectiveness of photodynamic therapy against Enterococcus faecalis, with and without the use of an intracanal optical fiber: an in vitro study. Photomed Laser Surg. 2011;29(12):803-808. doi:10.1089/pho.2011.2995.

29. Rios A, He J, Glickman GN, Spears R, Schneiderman ED, Honeyman AL. Evaluation of photodynamic therapy using a light-emitting diode lamp against enterococcus faecalis in extracted human teeth. J Endod. 2011;37(6):856-859. doi:10.1016/j.joen.2011.03.014.

30. Asnaashari M, Godiny M, Azari-Marhabi S, Tabatabaei FS, Barati M. Comparison of the antibacterial effect of 810 $\mathrm{nm}$ diode laser and photodynamic therapy in reducing the microbial flora of root canal in endodontic retreatment in patients with periradicular lesions. J Lasers Med Sci. 2016;7(2):99-104. doi:10.15171/jlms.2016.17.

31. Siddiqui SH, Awan KH, Javed F. Bactericidal efficacy of photodynamic therapy against Enterococcus faecalis in infected root canals: a systematic literature review. Photodiagnosis Photodyn Ther. 2013;10(4):632-643. doi:10.1016/j.pdpdt.2013.07.006.

32. Chrepa V, Kotsakis GA, Pagonis TC, Hargreaves KM. The effect of photodynamic therapy in root canal disinfection: a systematic review. J Endod. 2014;40(7):891-898. doi:10.1016/j.joen.2014.03.005.

33. Wainwright M, Phoenix DA, Marland J, Wareing DR, Bolton FJ. A study of photobactericidal activity in the phenothiazinium series. FEMS Immunol Med Microbiol. 1997;19(1):75-80.

34. Harris F, Chatfield LK, Phoenix DA. Phenothiazinium based photosensitisers--photodynamic agents with a multiplicity of cellular targets and clinical applications. Curr Drug Targets. 2005;6(5):615-627.

35. Usacheva MN, Teichert MC, Biel MA. The interaction of lipopolysaccharides with phenothiazine dyes. Lasers Surg Med. 2003;33(5):311-319. doi:10.1002/lsm.10226.

36. Rocas IN, Siqueira JF Jr, Aboim MC, Rosado AS. Denaturing gradient gel electrophoresis analysis of bacterial communities associated with failed endodontic treatment. Oral Surg Oral Med Oral Pathol Oral Radiol Endod. 2004;98(6):741-749. doi:10.1016/s1079210404006183.

37. Siqueira JF, Rocas IN, Moraes SR, Santos KR. Direct amplification of rRNA gene sequences for identification of selected oral pathogens in root canal infections. Int Endod J. 2002;35(4):345-351.

38. Molander A, Warfvinge J, Reit C, Kvist T. Clinical and radiographic evaluation of one- and two-visit endodontic treatment of asymptomatic necrotic teeth with apical periodontitis: a randomized clinical trial. J Endod. 2007;33(10):1145-1148. doi:10.1016/j.joen.2007.07.005.

39. Trindade AC, De Figueiredo JA, Steier L, Weber JB. Photodynamic therapy in endodontics: a literature review. Photomed Laser Surg. 2015;33(3):175-182. doi:10.1089/ pho.2014.3776.

40. Bonsor S, Nichol R, Reid T, Pearson G. Microbiological evaluation of photo-activated disinfection in endodontics (an in vivo study). British Dental Journal. 2006;200(6):337341.

41. Garcez AS, Nuñez SC, Hamblin MR, Ribeiro MS. Antimicrobial effects of photodynamic therapy on patients with necrotic pulps and periapical lesion. Journal of Endodontics. 2008;34(2):138-142. doi:10.1016/j. joen.2007.10.020.

42. Fimple JL, Fontana CR, Foschi F, et al. Photodynamic treatment of endodontic polymicrobial infection in vitro. J Endods. 2008;34(6):728-734.

43. Soukos NS, Chen PS-Y, Morris JT, et al. Photodynamic therapy for endodontic disinfection. $J$ Endod. 2006;32(10):979-984. doi:10.1016/j.joen.2006.04.007

44. Xu Y, Young MJ, Battaglino RA, et al. Endodontic antimicrobial photodynamic therapy: safety assessment in mammalian cell cultures. J Endod. 2009;35(11):1567-1572. doi:10.1016/j.joen.2009.08.002.

45. Amyra T, Walsh LT, Walsh LJ. An assessment of techniques for dehydrating root canals using infrared laser radiation. Aust Endod J. 2000;26(2):78-80.

46. Garcez AS, Nunez SC, Hamblim MR, Suzuki H, Ribeiro MS. Photodynamic therapy associated with conventional endodontic treatment in patients with antibiotic-resistant microflora: a preliminary report. J Endod. 2010;36(9):14631466. doi:10.1016/j.joen.2010.06.001.

47. Lim Z, Cheng JL, Lim TW, et al. Light activated disinfection: an alternative endodontic disinfection strategy. Aust Dent J. 2009;54(2):108-114. doi:10.1111/ j.1834-7819.2009.01102.x.

48. Shrestha A, Kishen A. The effect of tissue inhibitors on the antibacterial activity of chitosan nanoparticles and photodynamic therapy. J Endod. 2012;38(9):1275-1278. doi:10.1016/j.joen.2012.05.006.

49. Paque F, Balmer M, Attin T, Peters OA. Preparation of oval-shaped root canals in mandibular molars using nickel-titanium rotary instruments: a micro-computed tomography study. J Endod. 2010;36(4):703-707. doi:10.1016/j.joen.2009.12.020. 